Session 2306

\title{
An Artificial Neural Network Model for Preliminary Design of Reinforced Concrete Beam-Column
}

\author{
Mohammed E. Haque, Ph.D., P.E. \\ Texas A\&M University
}

\begin{abstract}
The dimensions of a beam-column cross-section and the area of reinforcing steel required to support a specific combination of axial load and moment can be established by using the column design interaction curves, where an interaction curve represents all possible combinations of axial load and moment that produce failure of the cross-section. The bending resistance of an axially loaded column about a particular skewed axis due to biaxial moments can be determined through iterations and lengthy calculations. These extensive calculations are multiplied when optimization of the reinforcing steel or column cross-section is required. This paper investigated the suitability of an Artificial Neural Network (ANN) for modeling a preliminary design of reinforced concrete beam-column. Neural computing is a relatively new field of artificial intelligence (AI), which tries to mimic the structure and operation of biological neural systems, such as the human brain, by creating an ANN on a computer. An ANN back-propagation multilayered model was developed to design a beam-column, which predicted column cross-section for a given set of inputs, which were concrete compressive strength, column types (Tied and Spiral), reinforcing steel ratio $(0.01-0.08)$, factored axial load, $P_{u}$, and moment, $M_{u}$. In the present research, several different ANN back-propagation trial models with different layers/slabs connections, weights and activation functions were trained. The presented back-propagation multi-layered neural net with logistic activation function, "Rotation" for pattern selection, and "TurboProp" for weight updates was the best one among all other trials, which converged very rapidly to reach an excellent statistical performance. The trained ANN back-propagation model was tested with several actual design data, and a comparative evaluation between the ANN model predictions and the actual designs was presented.
\end{abstract}

\section{Introduction}

Artificial neural network (ANN) is one of the artificial intelligence algorithms that relates to the class of machine learning. It mimics a human brain process of acquiring and retrieving knowledge. It models the biological neuron, which consists of nodes (cells) and links (axon). It is defined as "A computing system made up of a number of simple, highly interconnected processing elements, which processes information by its dynamic state response to external input $^{1}$. These ANNs are modeling techniques that are especially useful to address problems where solutions are not clearly formulated ${ }^{2}$ or where the relationships between inputs and outputs are not sufficiently known. ANNs have the ability to learn by example. Patterns in a 
series of input and output values of example cases are recognized. This acquired "knowledge" can then be used by the ANN to predict unknown output values for a given set of input values.

ANNs are composed of simple interconnected elements called processing elements (PEs) or artificial neurons that act as microprocessors. Each PE has an input and an output side. The connections are on the input side correspond to the dendrites of the biological original and provide the input from other PEs while the connections on the output side correspond to the axon and transmit the output. Figure 1 illustrates a simple PE of an ANN with the analogy of the human brain. The activation of the PE results from the sum of the weighted inputs and can be negative, zero, or positive. This is due to the synaptic weights, which represent excitatory synapses when positive $\left(\mathrm{w}_{\mathrm{i}}>0\right)$ or inhibitory ones when negative $\left(\mathrm{w}_{\mathrm{i}}<0\right)$. The PEs output is computed by applying the transfer function to the activation. The type of transfer function to be used depends on the type of ANN to be designed.

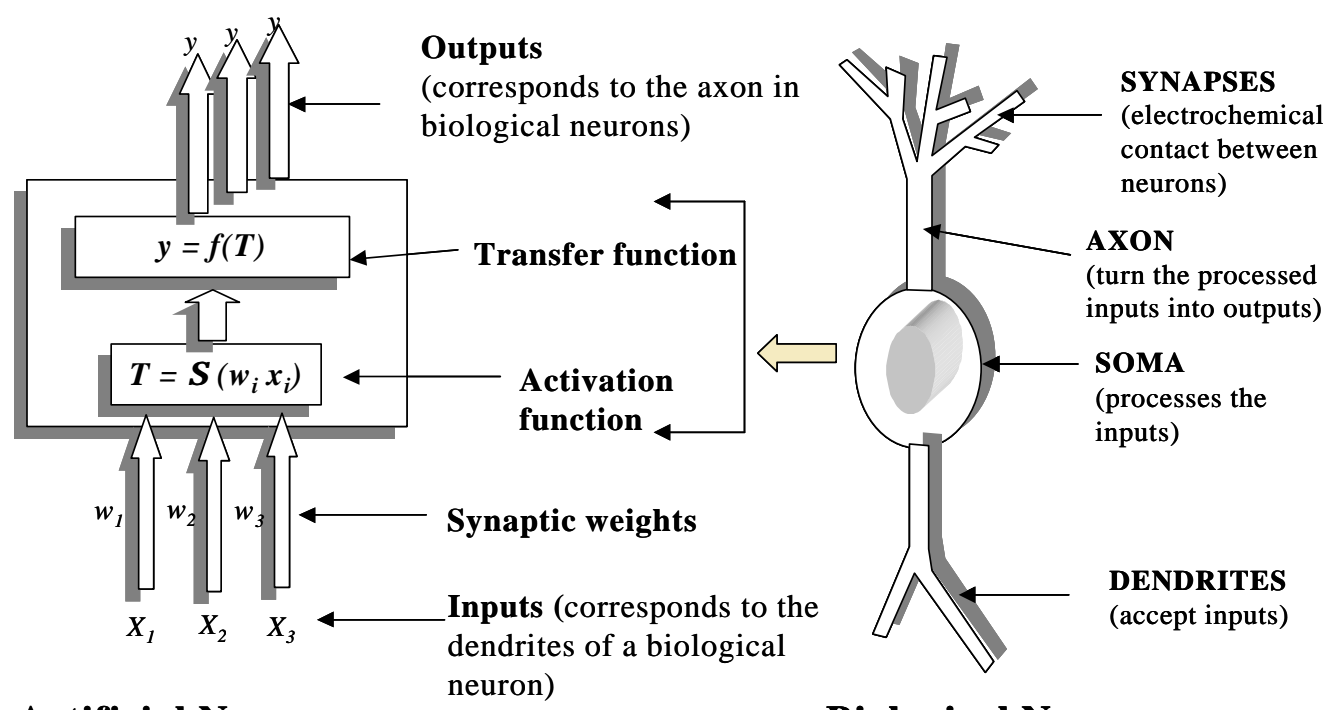

Artificial Neuron

Biological Neuron

Figure 1. Artificial Neural Networks: The Analogy to the Brain

Currently, back-propagation is the most popular, effective, and easy to learn model for complex networks ${ }^{3,4}$. For the last few years, the first author has been using various ANN back-propagation Multi-layer Perceptron (MLP) modeling techniques in materials science and engineering ${ }^{3-6}$. To develop a back-propagation neural network, a developer inputs known information, assigns weight to the connections within the network architecture, and runs in the networks repeatedly until the output is satisfactorily accurate. The weighted matrix of interconnections allows the neural networks to learn and remember ${ }^{7}$. In essence, back propagation training adapts a gradientdescent approach of adjusting the ANN weights. During training, an ANN is presented with the data thousands of times (called cycles). After each cycle, the error between the ANN outputs and the actual outputs are propagated backward to adjust the weights in a manner that is mathematically guaranteed to converge ${ }^{8}$.

This paper describes an ANN back-propagation Multi-layer Perceptron (MLP) model to design a beam-column, which predicts column cross-section for a given set of inputs: concrete 
compressive strength, column types (square tied and circular spiral), reinforcing steel ratio (0.01 - 0.08), factored axial load, $\mathrm{P}_{\mathrm{u}}$, and moment, $\mathrm{M}_{\mathrm{u}}$. The trained ANN back-propagation model has been tested with several actual design data, and a comparative evaluation between the ANN model predictions and the actual design has been presented.

\section{ANN Backpropagation Model}

The neural network used for the proposed models was developed with NeuroShell 2 software by Ward Systems Group, Inc., using a back-propagation architecture with multi- layers jump connection, where every layer (slab) is linked to every previous layer. Two ANN models were developed. The model-1 network was trained for column size. The inputs were type of column (Type $=1$ for square tied column, and type $=2$ for circular spiral column), factored load, $\mathrm{P}_{\mathrm{u}}$, Moment, $\mathrm{M}_{\mathrm{u}}$, and steel ratio, $\rho_{\mathrm{g}}$. In this model concrete ultimate compressive strength, $\mathrm{f}_{\mathrm{c}}$ ' was 4,000 PSI, and reinforcing steel yield strength, $\mathrm{f}_{\mathrm{y}}$ was 60,000 PSI. The model-2 network was trained for determining the values of $P_{o}, P_{n x}$, and $P_{n y}$, which determined the axial load capacity of a biaxial bending column using Bresler equation ${ }^{9}$ :

$$
1 / P_{n}=1 / P_{n x}+1 / P_{n y}-1 / P_{o} ; \text { for } P_{n}>=0.1 P_{o}
$$

Where $P_{n}=$ nominal axial load capacity of a column under biaxial bending.

$P_{n x}=$ nominal axial load capacity of a column when the load is placed at an eccentricity $\mathrm{e}_{\mathrm{x}}$.

$P_{n y}=$ nominal axial load capacity of a column when the load is placed at an eccentricity $\mathrm{e}_{\mathrm{y}}$.

$P_{o}=$ nominal axial load capacity of a column when the load is placed with a zero eccentricity.

The input for model-2 was $\mathrm{h}, \rho_{\mathrm{g}}$, e/h, and $\gamma$. The value of $\gamma$ was estimated using the equation: $\gamma=1-(5 / h)$, where the column size, $h$ was in inches. Figure 2 shows the column dimensions.

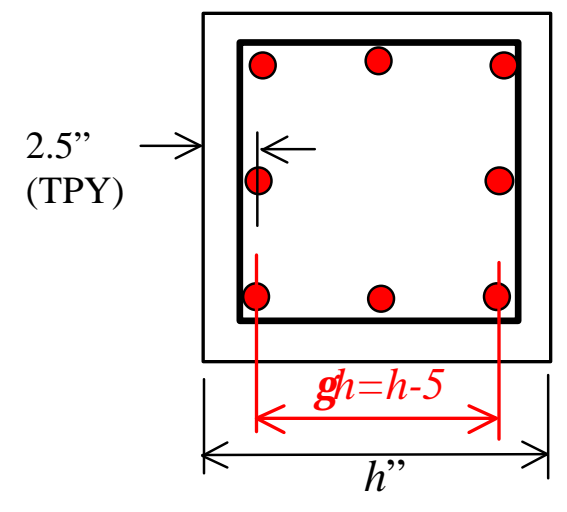

(a)

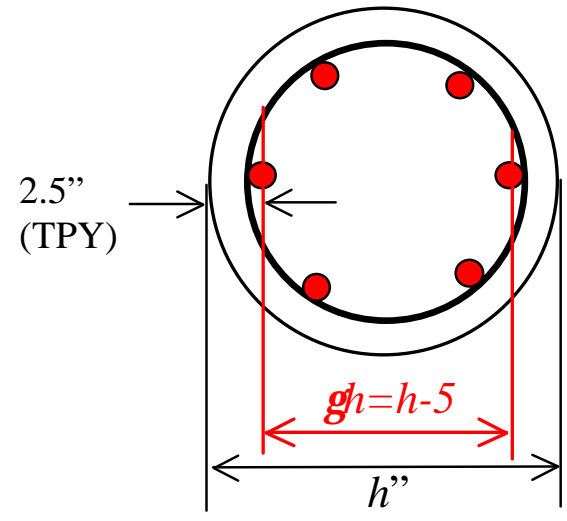

(b)

Figure 2. (a) Square tied column dimensions; (b) Circular spiral column dimensions.

The number of hidden neurons, for which the logistic activation function, $f(x)=1 /\{1+\exp (-x)\}$ was used, was determined according to the following formula ${ }^{10}$ : 


\section{Number of hidden neurons $=0.5($ Inputs + Outputs $)+\sqrt{ }($ Number of training patterns $)$}

Given the properties of the training data used: 4 inputs, 1 output, and 340 training patterns - the number of processing elements was determined to be 21 . The training data was obtained from a series of column design Interaction Diagrams with $\gamma=0.45,0.60,0.75$ and 0.9 for the column sizes in inches as determined by the equation: $h=5 /(1-\gamma)$. A set of data was randomly separated from the training set, and was not used in the training model. These data were used to evaluate the trained model.

\section{ANN Model Training}

Network training is an act of continuously adjusting their connection weights until they reach unique values that allow the network to produce outputs that are close enough to the desired outputs. This can be compared with the human brain, which basically learns from experience. The strength of connection between the neurons is stored as a weight-value for the specific connection. The system learns new knowledge by adjusting these connection weights. The learning ability of a neural network is determined by its architecture and by the algorithmic method chosen for training.

Several different ANN back-propagation trial models with different layers/slabs connections, weights and activation functions (including linear, Logistic, Gaussian, etc.) were trained with pattern selections including "Rotation" and "Random", and weight updates using Vanilla, Momentum and TurboProp. The presented ANN back-propagation Multi-layer Perceptron (MLP) model with logistic activation function, "Rotation" for pattern selection, and "TurboProp" for weight updates was the best one among all other trials, which converges very rapidly to reach the excellent statistical performance (as illustrated in System Performance). Figures 3 - 4 demonstrate the graphical comparisons between the actual column sizes and the network predicted column sizes during training phase of the ANN model. They clearly demonstrate very good agreement between the actual and predicted performance. Table 1 shows a good agreement between the column sizes and the ANN predicted column sizes during the evaluation phase.

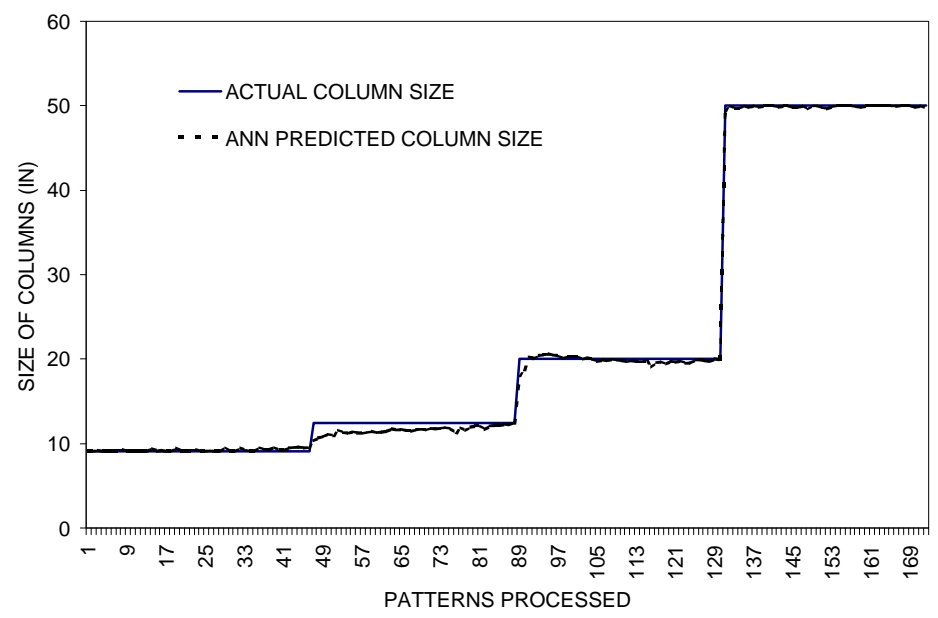

Figure 3. Square Tied Column Sizes for the ANN Training Patterns Processed 


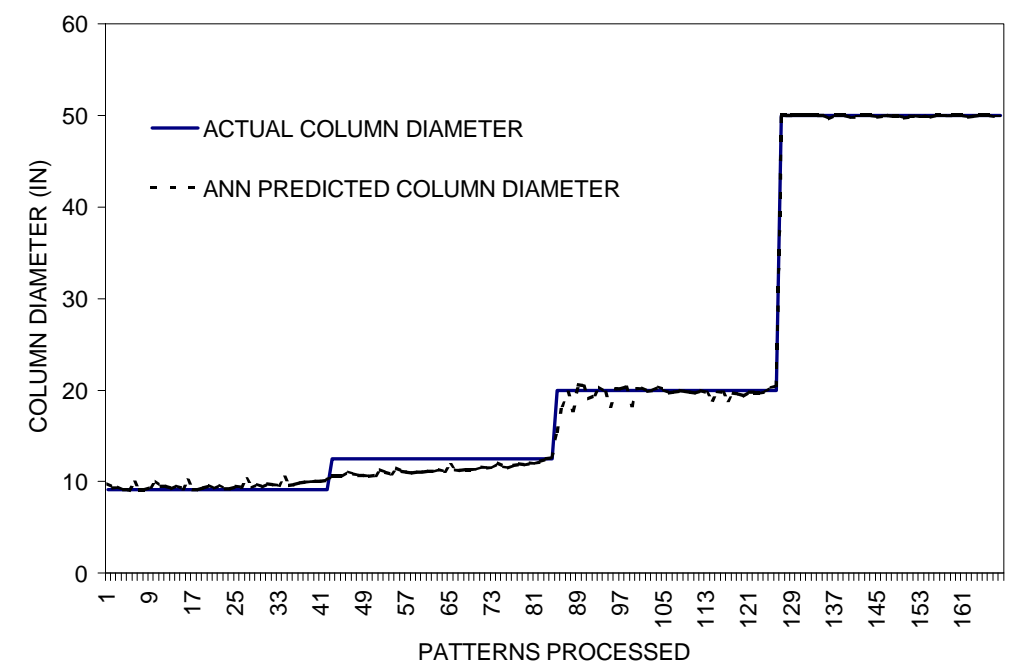

Figure 4. Circular Spiral Column Diameters for the ANN Training Patterns Processed

Table 1 Column size prediction during ANN model evaluation

\begin{tabular}{|c|c|c|c|c|c|c|c|}
\hline \multicolumn{4}{|c|}{$\begin{array}{l}\text { Square tied column with } \rho_{\mathrm{g}}=0.04 \\
\quad\left(\mathrm{f}_{\mathrm{c}}{ }^{\prime}=4 \mathrm{ksi} ; \mathrm{f}_{\mathrm{y}}=60 \mathrm{ksi}\right)\end{array}$} & \multicolumn{4}{|c|}{$\begin{array}{l}\text { Circular spiral column with } \rho_{\mathrm{g}}=0.04 \\
\qquad\left(\mathrm{f}_{\mathrm{c}}{ }^{\prime}=4 \mathrm{ksi} ; \mathrm{f}_{\mathrm{y}}=60 \mathrm{ksi}\right)\end{array}$} \\
\hline $\begin{array}{c}\mathrm{P}_{\mathrm{u}} \\
\text { (Kips) }\end{array}$ & $\begin{array}{c}\mathrm{M}_{\mathrm{u}} \\
\text { (ft-kip) }\end{array}$ & $\begin{array}{l}\mathrm{h} \\
\text { (in) }\end{array}$ & $\begin{array}{l}\text { ANN-h }{ }^{\text {(a) }} \\
\text { (in) }\end{array}$ & $\begin{array}{c}\mathrm{P}_{\mathrm{u}} \\
\text { (Kips) }\end{array}$ & $\begin{array}{c}\mathrm{M}_{\mathrm{u}} \\
\text { (ft-kip) }\end{array}$ & $\begin{array}{l}\mathrm{h} \\
\text { (in) }\end{array}$ & $\begin{array}{l}\text { ANN-h }{ }^{\text {(a) }} \\
\text { (in) }\end{array}$ \\
\hline 37.19 & 28.17 & 9.09 & 9.09 & 25.96 & 19.67 & 9.09 & 9.26 \\
\hline 56.20 & 29.80 & 9.09 & 9.09 & 51.93 & 19.67 & 9.09 & 9.39 \\
\hline 74.38 & 28.17 & 9.09 & 9.09 & 64.91 & 19.67 & 9.09 & 9.46 \\
\hline 90.91 & 27.55 & 9.09 & 9.09 & 82.11 & 18.66 & 9.09 & 9.52 \\
\hline 117.36 & 26.67 & 9.09 & 9.09 & 117.81 & 17.85 & 9.09 & 9.69 \\
\hline 165.29 & 25.04 & 9.09 & 9.27 & 186.94 & 14.16 & 9.09 & 9.98 \\
\hline 234.71 & 17.78 & 9.09 & 9.47 & 59.52 & 62.00 & 12.50 & 10.65 \\
\hline 90.63 & 94.40 & 12.50 & 10.98 & 122.72 & 63.92 & 12.50 & 11.07 \\
\hline 171.88 & 89.52 & 12.50 & 11.26 & 147.26 & 61.36 & 12.50 & 11.14 \\
\hline 218.75 & 91.15 & 12.50 & 11.57 & 189.60 & 59.25 & 12.50 & 11.33 \\
\hline 265.63 & 83.01 & 12.50 & 11.60 & 260.16 & 54.20 & 12.50 & 11.61 \\
\hline 343.75 & 71.61 & 12.50 & 11.76 & 376.13 & 39.18 & 12.50 & 11.91 \\
\hline 468.75 & 48.83 & 12.50 & 11.95 & 188.50 & 314.16 & 20.00 & 20.31 \\
\hline 280.00 & 466.67 & 20.00 & 20.28 & 376.99 & 251.33 & 20.00 & 18.57 \\
\hline 540.00 & 450.00 & 20.00 & 20.08 & 376.99 & 314.16 & 20.00 & 20.49 \\
\hline 640.00 & 426.67 & 20.00 & 19.98 & 565.49 & 282.74 & 20.00 & 20.07 \\
\hline 760.00 & 380.00 & 20.00 & 19.74 & 736.70 & 245.57 & 20.00 & 19.86 \\
\hline 960.00 & 320.00 & 20.00 & 19.81 & 1005.31 & 167.55 & 20.00 & 19.65 \\
\hline 1240.00 & 206.67 & 20.00 & 19.85 & 1374.45 & 5726.86 & 50.00 & 50.00 \\
\hline 2000.00 & 8333.33 & 50.00 & 49.97 & 2748.89 & 5726.86 & 50.00 & 50.00 \\
\hline 3750.00 & 7812.50 & 50.00 & 50.00 & 3141.59 & 5235.99 & 50.00 & 49.84 \\
\hline 4425.00 & 7375.00 & 50.00 & 50.00 & 3926.99 & 4908.74 & 50.00 & 49.86 \\
\hline 5250.00 & 6562.50 & 50.00 & 50.00 & 4908.74 & 4090.62 & 50.00 & 49.95 \\
\hline 6375.00 & 5312.50 & 50.00 & 50.00 & 6450.08 & 2687.53 & 50.00 & 50.00 \\
\hline
\end{tabular}

${ }^{\text {(a) }} \mathrm{ANN}-\mathrm{h}=\mathrm{ANN}$ predicted value of $\mathrm{h}$

Proceedings of the 2002 American Society for Engineering Education Annual Conference \& Exposition Copyright $\odot$ 2002, American Society for Engineering Education 


\section{System Performance}

The neural network used for the presented model demonstrated an excellent statistical performance as indicated by the $R^{2}$ and $r$-values as shown in Table 2. During network training, $R^{2}$ was obtained as 0.9980 and 0.9984 during network evaluation, which were very close to 1.0 indicating a very good fit between the actual and the network prediction. $R^{2}$ is a statistical indicator usually applied to multiple regression analysis, and can be calculated using the following formulae ${ }^{10}$ :

$$
R^{2}=1-\left(\operatorname{SSE} / S S_{y y}\right)
$$

Where $\operatorname{SSE}=\Sigma(y-\xi)^{2}, S S_{y y}=\Sigma(y-y)^{2}, y$ is the actual value, $¥$ is the predicted value of $y$, and $y$ is the mean of the $y$ values.

The correlation coefficient, $\mathrm{r}$ is a statistical measure of the strength of the relationship between the actual vs. predicted outputs. During network training, $r$-values were obtained as 0.9991 , and 0.9993 during network evaluation, which were very close to +1.0 indicating a very good fit between the actual and the network prediction. The formula for $\mathrm{r}$ :

$$
r=S S_{x y} / N\left(S S_{x x} S S_{y y}\right)
$$

Where $S S_{x y}=\Sigma x y-(1 / n)\left\{\left(\sum x\right)\left(\sum y\right)\right\} ; S S x x=\Sigma x^{2}-(1 / n)\left(\sum x\right)^{2} ; S S_{y y}=\Sigma y^{2}-(1 / n)(\Sigma y)^{2}$; Where $n$ equals the number of patterns, $x$ refers to the set of actual outputs, and $y$ refers to the predicted outputs. Table 2 shows the overall statistical performance of the trained ANN model.

Table 2 Statistical performance of the ANN trained model

\begin{tabular}{|l|c|c|}
\hline \multicolumn{1}{|c|}{ Items } & ANN - training phase & ANN - evaluation phase \\
\hline Pattern processed & 340 & 48 \\
\hline R Squared & 0.9980 & 0.9984 \\
\hline Correlation Coefficient, r & 0.9991 & 0.9993 \\
\hline Mean Squared Error & 0.529 & 0.425 \\
\hline Mean Absolute Error & 0.466 & 0.418 \\
\hline Minimum Absolute Error & 0.0 & 0.0 \\
\hline Maximum Absolute Error & 4.479 & 1.854 \\
\hline Percent within 5\% & 70.882 & 72.917 \\
\hline Percent within 5\% to 10\% & 18.529 & 18.750 \\
\hline Percent within 10\% to 20\% & 10.294 & 8.333 \\
\hline Percent within 20\% to 30\% & 0.294 & 0 \\
\hline Percent > 30\% & 0 & 0 \\
\hline
\end{tabular}

\section{Examples}

Several reinforced concrete short columns with uniaxial and biaxial bending moments were designed using the ANN models; a few of the results are shown in Tables 3 and 4. For predicting the required column sizes, the inputs for the ANN model-1 were type of column (Type 
$=1$ for square tied column, and type $=2$ for circular spiral column), factored load, $\mathrm{P}_{\mathrm{u}}$, Moment, $\mathrm{M}_{\mathrm{u}}$, and steel ratio, $\rho_{\mathrm{g}}$ (selected within 0.01 to 0.08 ). For a circular spiral column with biaxial moments, the resultant moment, $\mathrm{M}_{\mathrm{u}}$ was calculated by taking the square root of the sum of the squares of the moments from two perpendicular directions, $\mathbf{M}_{\mathrm{ux}}$ and $\mathbf{M}_{\mathrm{uy}}$. For a square tied column with biaxial moments, $\mathrm{M}_{\mathrm{u}}$ for the ANN model-1 was calculated using the equation ${ }^{11}$ :

$$
\phi M_{n x}{ }^{\prime}=M_{u x}+M_{u y}\{(1-\beta) / \beta\}, \text { where } \beta \text { varies from } 0.55 \text { to } 0.65
$$

In the example problems, the load-contour curvature with the parameter, $\beta=0.65$ was used. Once the size of the squire tied column with biaxial bending was predicted through the ANN model-1, a reasonable size was selected, and the capacity of the column, $\phi P_{n}$ was calculated using the Bresler equation as stated earlier from the values of $P_{n x}, P_{n y}$, and $P_{o}$. The values of $P_{n x}$, $P_{n y}$, and $P_{o}$ were obtained from the ANN model-2. In general, all the cases, the ANN models produced pretty good results in determining column sizes with varying steel ratio.

Table 3 Column size prediction using ANN Model-1

\begin{tabular}{|c|c|c|c|c|c|c|}
\hline $\begin{array}{c}\text { Column } \\
\text { Type }\end{array}$ & $\begin{array}{c}\mathrm{P}_{\mathrm{u}} \\
\text { (Kips) }\end{array}$ & $\begin{array}{c}\mathrm{M}_{\mathrm{ux}} \\
\text { (ft-kips) }\end{array}$ & $\begin{array}{c}\mathrm{M}_{\mathrm{uy}} \\
\text { (ft-kips) }\end{array}$ & $\rho_{\mathrm{g}}$ & $\begin{array}{c}\mathrm{h} \\
\text { (in) }\end{array}$ & $\begin{array}{c}\text { Selected } \mathrm{h} \\
\text { (in) }\end{array}$ \\
\hline 1 & 640 & 330 & 0 & 0.03 & 19.55 & 20 \\
\hline 1 & 600 & 140 & 0 & 0.03 & 15.60 & 16 \\
\hline 2 & 408 & 204 & 0 & 0.015 & 18.36 & 20 \\
\hline 2 & 424 & 127 & 0 & 0.041 & 15.64 & 16 \\
\hline $1^{\text {(a) }}$ & 378 & 189 & 158 & 0.02 & 19.04 & 22 \\
\hline $1^{\text {(b) }}$ & 432 & 108 & 144 & 0.03 & 16.23 & 18 \\
\hline 2 & 378 & 189 & 158 & 0.02 & 21.09 & 22 \\
\hline 2 & 432 & 108 & 144 & 0.03 & 17.61 & 18 \\
\hline
\end{tabular}

Note:

(a), (b) See Table 4 for Column Load Capacity by Bresler Equation using ANN Model-2

Table 4 Column Load Capacity by Bresler Equation using ANN Model-2

\begin{tabular}{|c|c|c|c|c|c|c|}
\hline $\begin{array}{c}\mathrm{P}_{\mathrm{o}} \\
(\mathrm{Kips})\end{array}$ & $\begin{array}{c}\mathrm{P}_{\mathrm{nx}} \\
(\mathrm{Kips})\end{array}$ & $\begin{array}{c}\mathrm{P}_{\mathrm{ny}} \\
(\mathrm{Kips})\end{array}$ & $\begin{array}{c}\mathrm{P}_{\mathrm{n}} \\
(\mathrm{Kips})\end{array}$ & $\begin{array}{c}\text { Check } \\
\mathrm{P}_{\mathrm{n}}>=0.1 \mathrm{P}_{\mathrm{o}}\end{array}$ & $\begin{array}{c}\varphi \mathrm{Pn} \\
(\text { Kips })\end{array}$ & $\begin{array}{c}\text { Check } \\
\varphi \mathrm{P}_{\mathrm{n}}>=\mathrm{P}_{\mathrm{u}}\end{array}$ \\
\hline${ }^{1(\mathrm{a})} 1817.25$ & 824.12 & 945.75 & 581.23 & OK & 406.86 & OK \\
\hline${ }^{1(\mathrm{~b})} 1633.52$ & 1068.44 & 934.89 & 717.66 & OK & 502.36 & OK \\
\hline
\end{tabular}

Note:

1(a), 1(b) See Table 3 for the tied column size

\section{Educational Significance}

It is increasingly important to go beyond traditional departmental course curriculum boundaries for some areas of science and engineering education. ANN is one such field, because although electrical/computer engineers developed it largely, its applications are very extensive and 
interdisciplinary. Especially the graduate students should be encouraged to learn various applications of contemporary computing techniques including artificial neural network, genetic algorithm, etc. This paper is an example of ANN's interdisciplinary application in the fields of structural engineering.

\section{Conclusions}

This paper investigated the suitability of an Artificial Neural Network (ANN) for modeling a preliminary design of reinforced concrete beam-column. It was established in this paper that an ANN back-propagation model with Multi-layer Perceptron (MLP) network could be applied to design reinforced concrete beam-columns. The neural networks demonstrated an excellent statistical performance in the network training as well as in the evaluation of the trained networks. Several reinforced concrete short columns with uniaxial and biaxial bending moments were studied and found that the ANN models produced pretty good results in determining column sizes with varying steel ratio. The application of an ANN model certainly minimized the extensive calculations, especially required for column with biaxial bending during the optimization of the reinforcing steel or the column cross-section.

\section{Bibliography}

1. Caudill, M. (1987) "Neural Network Primer: Part 1. "Al Expert, Dec., pp 46-52.

2. Chester, M. (1993) Neural Networks - A Tutorial, Prentice Hall: Englewood Cliffs, NJ, USA

3. Haque, M.E., Sudhakar, K.V. (2001) ANN based Prediction Model for Fatigue Crack Growth in DP Steel. International Journal of Fatigue \& Fracture of Engineering Materials and Structures, Vol. 24 (1), pp. 63-68.

4. Haque, M.E., Sudhakar, K.V. (2001) Prediction of Corrosion-Fatigue behavior of DP Steel through Artificial Neural Network. International Journal of Fatigue, Vol. 23 (1), pp. 1-4.

5. Sudhakar, K.V., and Haque, M.E. (2001) "Mechanical behavior of Powder Metallurgy steel - Experimental Investigation and Artificial Neural Network-Based Prediction Model, "Journal of Materials Engineering and Performance, 10(1), pp. 31-36.

6. Haque, M.E., and Sudhakar, K.V. (2000) "An Artificial Neural Network Prediction for Dry Sliding Wear in Fe2\% Ni based PM Alloy," Brazilian Journal of Materials Science and Engineering, Vol. 3, N.1, pp. 37-44.

7. Obermeier, K., and Barron, J. (1989) Time to Get Fried Up, BYTE, 14 (8) pp. 227-233

8. Rumelhart, D., Hinton, G., and Williams, R. (1986) "Parallel distributed processing," MIT Press, Cambridge, MA., USA

9. Bresler, B (1960) "Design Criteria for Reinforced Concrete Column Under Axial and Biaxial Bending," ACI Proc., Vol. 57, pp. 481-490.

10. NeuroShell 2 User's Manual (1996) Ward Systems Group, Inc., Frederick, MD, USA

11. Design Handbook, vol. 2, Columns, ACI Publ. SP-17a(78), 1978.

\section{MOHAMMED E. HAQUE}

Mohammed E. Haque is an Associate Professor of the Department of Construction Science at Texas A\&M University at College Station, Texas. He has over fifteen years of professional experience in analysis, design, and investigation of building, bridges and tunnel structural projects of various city and state governments and private sectors. Dr. Haque is a registered Professional Engineer in the states of New York, Pennsylvania and Michigan, and members of ASEE, ASCE, and ACI. Dr. Haque received a BSCE from Bangladesh University of Engineering and Technology, a MSCE and a Ph.D. in Civil/Structural Engineering from New Jersey Institute of Technology, Newark, New Jersey. His research interests include fracture mechanics of engineering materials, composite materials and advanced construction materials, computer applications in structural analysis and design, artificial neural network applications, knowledge based expert system developments, application based software developments, and buildings/ infrastructure/ bridges/tunnels inspection and database management systems. 